\title{
O gesto alegórico enquanto forma de representação na crítica epistemológica de Walter Benjamin.
}

\author{
Joaquim Iarley Brito Roque ${ }^{1}$
}

\section{Resumo}

$\mathrm{Na}$ interioridade da produção filosófica de Walter Benjamin (1892-1940) reside implicitamente uma concepção que merece ser alvo de investigação, a saber, a da necessidade de se fundar uma "gnoseologia" que possa alcançar a lógica fragmentária da realidade atual sem encobrir todos os elementos que a constituem. Neste sentido Benjamin lança ainda na introdução crítica-epistemológica de sua obra Origem do Drama Barroco Alemão e em sua Passagens conceitos como os de alegoria, monadologia, montagem, dentre outros, em uma perspectiva dialética que de forma inovadora e original tenta apontar para a necessidade de levantarmos questões referentes ao primado do fragmentário sobre o sistemático no âmbito dos métodos e das teorias filosóficas de nosso tempo. Ressaltando as particularidades de tal proposta epistemológica, como a nítida crítica direcionada para a ideia de filosofia enquanto sistema e sua defesa do modelo tratadístico e da representação, tentaremos apontar quais os elementos presentes na crítica do conhecimento posta por Benjamin que o levam a afirmar que a ideia de filosofia enquanto sistema traz consigo o perigo da instauração de um sincretismo metodológico que tenta pretensamente capturar a verdade numa rede linear de entendimento. Apresentar tais apontamentos é o que se propõe o presente trabalho.

Palavras-chave: teoria do conhecimento, alegoria, monadologia.

\begin{abstract}
In the interior of the production of Walter Benjamin (1892-1940) lies implicitly a concept that deserves investigation, namely the need to establish a "gnoseology" that can reach the fragmentary logic of the current reality without cover all elements that constitute it. In this sense Benjamin also launched in the introduction-epistemological

\footnotetext{
${ }^{1}$ Mestrando em Filosofia pela Universidade Federal do Ceará (UFC), membro do Grupo de Estudos Walter Benjamin e a Filosofia Contemporânea (GEWEBE), e graduando em Psicologia pela Faculdade de Tecnologia Intensiva (FATECI). E mail: iarleybr@ hotmail.com
} 
critique of his work Origin of German Baroque Drama and its Passages concepts such as allegory, monadology, assembly, among others, in a dialectical perspective to an innovative and original attempt to point to the need can raise issues about the rule of fragmented within the systematic methods and philosophical theories of our time. Emphasizing the particularities of this epistemological proposal, as the sharp criticism directed at the idea of philosophy as a system and its defense of the model presentation and representation, we will try to point out which elements in the criticism of knowledge brought by Benjamin that lead him to say that idea of philosophy as a system brings with it the danger of establishing a methodological syncretism allegedly trying to capture the truth in a linear network of understanding. Submit such notes is what will the present work.

Keywords: fragmentary, theory of knowledge, allegory, monadology, representation.

A tese sobre a Origem do Drama Barroco Alemão apresentada por Walter Benjamin à Universidade de Frankfurt em 1925, como dissertação (Habilitationsschrift) para conquistar a Livre-docência e as suas Passagens, configuram obras de suma importância, digamos até obrigatórias, para quem quer se lançar sobre os inúmeros escritos benjaminianos. Tal importância está diretamente ligada à necessidade de se conhecer uma via mais segura de entendimento da totalidade de seu pensamento, que por muitas décadas foi compreendido a partir de uma leitura que apresentava os conceitos de forma desarticulada, como se este fosse o único procedimento possível diante de uma filosofia dita "aforismática". Portanto, visto que a inadequação metodológica pode nos levar a uma compreensão bastante limitada de determinada perspectiva ou corrente filosófica, a leitura de seu prólogo epistemológico-crítico apresentado em seu livro sobre o Drama Barroco merece mais atenção.

Benjamin inicia sua exposição quanto à Teoria do Conhecimento na medida em que afirma sob qual modelo de filosofia pretende erigir suas reflexões. Já na introdução de sua principal obra, ele tece de imediato uma crítica a toda proposta de filosofia que se mostre subjugada e reduzida ao conceito de sistema, pois, segundo o seu entendimento, este conceito, característico da filosofia, defendido e exposto por G.W. F. Hegel (1770-1831) e aceita ainda por alguns pensadores do séculos posteriores, faz a reflexão filosófica sofrer uma constante ameaça. 
Na medida em que a filosofia é determinada por esse conceito de sistema, ela corre o perigo de acomodar-se num sincretismo que tenta capturar a verdade numa rede estendida entre vários tipos de conhecimento, como se a verdade voasse de fora para dentro. ${ }^{2}$

Devemos entender que uma proposta filosófica, dita sistemática, possui algumas características que devem por nós ser apresentadas a título de diferenciação. Um sistema filosófico só pode ser compreendido como tal se, no momento de sua construção, a totalidade de seu discurso não tenha se levantado a partir de algumas premissas iniciais que, quando ligadas umas as outras dedutivamente, possibilitam a construção de um projeto filosófico coerente, coeso e lógico, o qual permite a compreensão do universal numa rede estendida de relações interdependentes. Este entendimento de filosofia enquanto saber absolutamente sistemático configura para Benjamin a imagem de um abismo profundo onde muitos pensadores tendem a cair. Somente aqueles que não se deixam levar pela ilusória clareza do sistema podem compreender a verdadeira relação entre o universal e o particular. ${ }^{3}$

Benjamin não tece uma crítica destrutiva e vazia, que sem propor algo novo faça seu apontamento se dissipar no abismo do nada, ele prefere e propõe cobrir esse vazio apresentado pelo sistema com o modelo do tratado, onde o "Método é caminho indireto, é desvio".4 Assim, para não cair em uma absoluta ausência de rigor metodológico, Benjamin elege e aplica em seus escritos o modelo tratadístico, pois, na sua concepção, os tratados, assim como os mosaicos da idade média, "justapõem elementos isolados e heterogêneos e nada manifesta com mais força o impacto transcendente, quer da imagem sagrada quer da verdade". 5 Tal afirmação aponta para o fato de que a mudança de postura filosófica diante da realidade é uma exigência daquele que pretende defender a descontinuidade perante a falsa ideia de coerência ininterrupta do sistema.

Segundo Sérgio Paulo Rouanet, "para Benjamin o caminho da verdadeira investigação filosófica é o da representação"6 posta no tratado, mas não qualquer representação, e sim aquela que por uma mudança de direção do universal se encontra com as ideias.

\footnotetext{
${ }^{2}$ BENJAMIN, Walter. Origem do drama barroco alemão, p.50.

${ }^{3}$ Trata-se aqui de abandonar um modelo de filosofia que se mostrou durante séculos bastante rigoroso em seu método, mas que não foi capaz de acompanhar e analisar adequadamente a totalidade de fenômenos que se apresentaram na modernidade.

${ }^{4}$ BENJAMIN, Walter. Origem do Drama Barroco Alemão, p.50.

${ }^{5}$ Ibidem, p.51.

${ }^{6}$ BENJAMIN, Walter. “Apresentação”, in Origem do Drama Barroco Alemão, p.13.
} 
Na concepção benjaminiana, a ideia não deve se colocar distante do particular, do mundo dos fenômenos, pois essas ideias só deixam de ser "obscuras" na medida em que os fenômenos passam a reconhecê-las envolvendo todo seu âmbito periférico. Longe das particularidades dos fenômenos, as ideias são vazias, assim como os fenômenos se tornam vazios longe das ideias. Nesse sentido, “a tarefa do filósofo é assim a de injetar nas ideias o sangue vigoroso da empiria e de salvar os fenômenos, guardando-os no 'recinto das ideias"'.7

Assim, deixamos claro que para o pensador judeu alemão o papel da reflexão filosófica e epistemológica é sempre buscar uma aproximação das ideias com os fenômenos e assim "guardá-los" na própria ideia, para que assim, o particular não perca sua singularidade em detrimento do universal. Como afirma Rouanet:

\begin{abstract}
Mas a empiria não pode penetrar diretamente no mundo das ideias. Donde a função mediadora do conceito. Pelo conceito, as coisas são divididas em seus elementos constitutivos, e enquanto elementos, podem ingressar na esfera das ideias, salvando-se; inversamente, pelo conceito, as ideias podem ser representadas, tornando-se concretas, graças à empiria desmembrada em seus elementos materiais. Os conceitos conseguem assim "de um golpe dois resultados: salvar os fenômenos e representar as ideias. ${ }^{8}$
\end{abstract}

Apontando para a diferenciação fundamental existente entre a ideia e o conceito, Benjamin não só torna mais lúcida sua posição quanto aos limites do universal posto pelo conceito, como também demonstra sua desconfiança para com a filosofia sistemática de Hegel. Se o judeu alemão encontrava no sistema universal hegeliano o apontamento de que o conceito deve se colocar como o ponto mais alto do trabalho do espírito, no seu entendimento, também a crítica direcionada ao entendimento de que os conceitos são as vias mais seguras na apreensão da realidade, de algum conteúdo de verdade, também deve ser levada a sério. Segundo Benjamin, o conceito entendido conforme apontava a filosofia hegeliana só pode ser tomado como um mediador, presente entre um fenômeno singular e uma ideia universal. ${ }^{9}$ Nas ideias reside o universal, só elas são universais. Os conceitos, assim, precisam das ideias para se agruparem e serem divididos em seus elementos constitutivos, evitando que estes se percam no mundo dos fenômenos sem que tenham acesso à ideia de

\footnotetext{
${ }^{7}$ Ibidem, p.13.

${ }^{8}$ BENJAMIN, Walter. Origem do Drama Barroco Alemão, p. 57.

${ }^{9}$ A aplicação desse modelo na realidade da sociedade civil e sociedade política significa que o particular coincide com o universal. (Cf. HEGEL, G. W. F. Princípios da Filosofia do Direito. São Paulo: Martins Fontes, 2001, p.16).
} 
totalidade. Já quanto à condição da ideia, Benjamin afirma que esta necessita da vitalidade que os conceitos proporcionam enquanto singulares.

Na perspectiva do judeu alemão, o conceito não pode ser universal como propõe a filosofia hegeliana, pois a parte para Hegel só existe em detrimento do todo. 0 conceito, inerente à ideia de totalidade e universalidade na filosofia hegeliana, precisa sempre se manter ligado à singularidade dos fenômenos, à realidade empírica.

Mas se o universalismo fraudulento das ciências ou o sistema é impotente para salvar as coisas, é porque as homogeneíza, ignorando as diferenças entre seus elementos. Salvar as coisas é preservar essas diferenças. Subsumidas na média, esses extremos desaparecem; é preciso, ao contrário, manter sua integridade. ${ }^{10}$

Por fim, podemos afirmar que Benjamin ao lançar seus apontamentos sobre a relação entre o particular e o universal, entre a ideia e o conceito, pretende fundar uma dialética não hegeliana, pois no seu entendimento as ideias não estão no conceito, este que representa a simples mediação entre o particular e o universal, ou seja, as ideias não se dissolvem no pseudo-universal da média.

Quanto ao caráter mais profundo da temática por nós colocada em questão, podemos afirmar que um melhor entendimento da totalidade dos apontamentos benjaminianos nos exigiria de pronto uma remissão à sua filosofia da linguagem. Embora nosso recorte não pretenda atingir um propósito tão amplo, recortaremos e analisaremos brevemente a relação indissolúvel entre dois conceitos complementares e primordiais no que concerne à concepção epistemológica desenvolvida por Benjamin, a saber, a relação entre mônada e linguagem.

\section{A monadologia e a linguagem}

Walter Benjamin encontra na crítica desenvolvida por Leibniz (1646-1716) à teoria mecanicista de interpretação do mundo posta por Descartes a proposta que faltava para formatar uma imagem mais coerente de sua concepção epistemológica. Em sua obra intitulada A Monadologia, Leibniz tenta definir a mônada enquanto elemento simples e imaterial pelo qual são constituídas as ínfimas partes da matéria; uma força simples e irredutível, que contém em si mesma a fonte de toda a atividade material do

\footnotetext{
${ }^{10}$ BENJAMIN, Walter. “Apresentação", in Origem do Drama Barroco Alemão, p.14.
} 
universo. Benjamin vai traçar uma leitura bastante particular deste conceito e levá-lo ao âmbito de seu estudo sobre o drama barroco ao afirmar que a ideia então é mônada, pois, em sua singularidade está presente a "totalidade do mundo das ideias".

A apreensão da amplitude e dimensão que o conceito de mônada tem na teoria do conhecimento benjaminiana só pode ser compreendida quando tomamos como base a afirmação apresentada por Rouanet ${ }^{11}$ de que o conceito de "origem" (Ursprung), trabalhado por Benjamin, não nos deve remeter ao conceito de gênese, pois, para a filosofia do judeu alemão, "origem" significa um "salto em direção ao novo, onde o objeto originado se liberta do vir-a-ser e da extinção". Nesse sentido as ideias que têm sua origem na história, de forma intemporal, remetem sempre à sua pré-história e à sua pós-história.

E a estrutura dessa ideia, resultante do contraste entre seu isolamento inalienável e a totalidade, é monadológica. A ideia é mônada. O Ser que nela penetra com sua pré e pós-história traz em si, oculta, a figura do restante do mundo das ideias, da mesma forma que segundo Leibniz, em seu Discurso sobre Metafísica, de 1686, em cada mônada estão indistintamente presentes todas as demais. ${ }^{12}$

Em Benjamin a ideia de mônada se apresenta mais claramente aos nossos olhos quando o autor trata de fenômenos aparentemente muito particulares, como na sua obra das Passagens. Quando Benjamin disserta sobre Paris, está tratando dos cafés, das galerias, dos bulevares. A leitura da cidade moderna (no sentido restrito) não aparece em Benjamin como uma totalidade. Ele escolhe partes eleitas, pedaços, "fragmentos" que não podem ser entendidos simplesmente como partes, mas principalmente enquanto mônadas. As mônadas se apresentam como "indivíduos exemplares", na perspectiva em que esses revelam uma época. Como afirma Benjamin na Exposé de 1935:

Um guia ilustrado de París diz: "Estas passagens, uma recente invenção do luxo industrial, são galerias cobertas de vidros e com paredes revestidas de mármore, que atravessam quarteirões inteiros cujos proprietários se uniram para esse tipo de especulação. Em ambos os lados dessas galerias, que recebem a luz do alto, alinham-se as lojas mais elegantes, de modo que tal passagem é uma cidade, um mundo em miniatura. ${ }^{13}$

Analisar a ideia monadologicamente significa ter acesso tanto ao particular quanto ao todo. Segundo Benjamin, a verdade só pode ser encontrada no ser livre da

\footnotetext{
${ }^{11}$ Cf. BENJAMIN, Walter. Origem do Drama Barroco Alemão, p.18.

12 BENJAMIN, Walter. Origem do Drama Barroco Alemão, pp.69-70.

${ }^{13}$ BENJAMIN, Walter. Passagens. Tradução de Irene Aron. Belo Horizonte: Editora da UFMG, 2007, p.40.
} 
fenomenalidade e esse ser livre é o "nome" enquanto ideia. "A ideia é algo de linguístico, é o elemento simbólico presente na essência da palavra".14

No entendimento benjaminiano, a teoria platônica afirma que as ideias se situam em uma realidade à parte do mundo das coisas, elas são realidades superiores que nós só poderíamos apreender por uma intuição intelectual. Segundo Leandro Konder, em $O$ Marxismo da Melancolia, ${ }^{15}$ o historiador Richard Wolin afirma que na origem da concepção de linguagem elaborada por Benjamin se achavam as teorias de um teólogo do século XIII, chamado Abraham Abulafia, comentador assíduo da Kabbala, para o qual a verdadeira redenção dos seres humanos só seria possível através de uma recuperação das experiências que a humanidade viveu na sua origem e a experiência mais marcante de todas seria a da gênese da linguagem, do verbo, mediante o qual Deus criou o mundo. A apropriação deste verbo pelo homem ocasionou além da separação entre criar e conhecer, um duplo movimento contraditório, a saber, o de refinamento da linguagem e de sua degradação.

Nesta imagem original do paraíso os homens inventavam nomes para as coisas de forma muito mais próxima, direta e essencial do que após a "queda" da dimensão nomeadora da linguagem. Portanto, é na linguagem adamítica que reside a possibilidade de encontrar as ideias de uma forma não-intencional. Porém, vale ressaltar que como afirma Konder:

Após a sua assimilação da perspectiva marxista, nos anos trinta, os fenômenos da degradação da dimensão nomeadora da linguagem e do uso crescente instrumental das palavras, em função comunicativa, passaram a ser analisados menos em decorrência do pecado original e da expulsão do paraíso do que em consequência da ascensão da burguesia e do modo de produção capitalista. ${ }^{16}$

Se para o filósofo alemão Martin Heidegger (1889-1976) em A essência da linguagem, "a linguagem é a casa do ser",17 para Benjamin, é na linguagem adamítica que encontramos a ideia enquanto mônada. A linguagem adamítica desperta as coisas quando as chama pelo seu verdadeiro nome. Já a linguagem, na sua dimensão comunicativa, transforma o nome em palavra, célula de um sistema complexo de

\footnotetext{
${ }^{14}$ BENJAMIN, Walter. Origem do Drama Barroco Alemão, p.58.

${ }^{15}$ Cf. KONDER, Leandro, Walter Benjamin: O marxismo da melancolia. Rio de Janeiro: Campus, 1989, p.31.

${ }^{16}$ Ibidem

${ }^{17}$ HEIDEGGER, Martin, A essência da linguagem in A caminho da linguagem. Petrópoles: Vozes, 2003, p. 127
} 
signos. ${ }^{18}$ Para Benjamin, a ideia enquanto representação da mônada, da imagem do todo, está inscrita na ordem do "nome". Neste sentido devemos nos indagar: como e onde podemos encontrar na contemporaneidade esta dimensão nomeadora da linguagem? 0 pensador judeu alemão responde que podemos encontrá-la no ato da recordação (anamnesis), na análise da palavra profana, na lembrança da dimensão nomeadora original. Rouanet, captando vivamente a dimensão da concepção benjaminiana da linguagem afirma que "o drama barroco, em sua existência empírica é o fenômeno, e como Nome é a ideia"19. Então como Walter Benjamin vai promover sua leitura bastante original do drama barroco enquanto representação, enquanto ideia?

\title{
A alegoria e o Barroco
}

Como sabemos, em Origem do Drama Barroco Alemão, Benjamin discorre sobre várias peças de teatro escritas por autores alemães do século XVII; são peças, em geral, conhecidas apenas por alguns poucos especialistas, portanto, não nos cabe uma análise minuciosa de tais escritos. No entanto, nos importa apontar que o pensador judeu alemão não estava tratando simplesmente do que costumamos chamar de "literatura morta", embora Asja Lacis (1891-1979), segundo Konder, tenha julgado que sim. 0 judeu alemão estava, na realidade, promovendo uma revisão no próprio conceito de "barroco" tradicionalmente utilizado pela maioria dos historiadores da literatura. Mas como foi possível a realização desta revisão? Benjamin afirma que:

\begin{abstract}
A história filosófica, enquanto ciência da origem, é a forma que permite a emergência, a partir dos extremos mais distantes e dos aparentes excessos do processo de desenvolvimento, da configuração da ideia, enquanto Todo caracterizado pela possibilidade de uma coexistência significativa desses contrastes. A representação de uma ideia não pode de maneira alguma ser vista como bem-sucedida, enquanto o ciclo dos extremos não for virtualmente percorrido". 20
\end{abstract}

Foi pela "análise dos extremos"21 que nosso crítico contrapôs o "drama barroco" à tragédia clássica, sustentando que as duas formas são expressões de dois universos

\footnotetext{
${ }^{18}$ Para Benjamin, as terminologias são tentativas mal sucedidas de nomeação em que a intenção tem um peso maior que a linguagem. (Cf. BENJAMIN, Walter. Origem do Drama Barroco Alemão, p.59).

${ }^{19}$ BENJAMIN, Walter. Origem do Drama Barroco Alemão, p.17.

${ }^{20}$ BENJAMIN, Walter. Origem do Drama Barroco Alemão, p.69.

${ }^{21}$ Ibidem, pp.29; 57.
} 
espirituais distintos: a tragédia, através da piedade e do terror, provoca a catarse purificadora e nesta, um acontecimento único manifesta um conflito que está sendo julgado por uma instância mais alta; o "drama barroco" se passa num palco que não é um lugar real, que é um lugar "dialeticamente dilacerado", transformado em espaço interno do sentimento, "sem nenhuma relação com o cosmo". Enquanto a tragédia introjeta a violência mítica, o drama introjeta a história como catástrofe, assim, a corte é o palco da história da ambição e do poder, retrato da degradação da civilização. Neste sentido, o espaço do "drama barroco" pressupõe espectadores inseguros, submergidos na iminência do movimento da história, condenados a refletir melancolicamente sobre problemas insolúveis; a "instância mais alta" não é a mais competente para formular julgamentos claros, os valores absolutos estão morrendo.

Segundo a concepção desenvolvida por Benjamin, desde o barroco estamos distantes da "interioridade não contraditória do classicismo", que era capaz de se expressar pela simplicidade e luminosidade dos símbolos. Se "cada pessoa, cada coisa, cada relação pode significar qualquer outra",22 devemos seguramente nos expressar pela via alegórica. Ou seja, o recurso da alegoria nos é imposto pelas condições históricas em que nos encontramos, pois, somos sobreviventes de uma destruição de todos os valores antigos, que foram transformados em escombros pela mercantilização da vida. Como afirma Benjamin: "As alegorias são, no reino dos pensamentos, o que as ruínas são no reino das coisas". 23

Entender o gesto alegórico, o "abismo" baudelaireano - abismo do espaço, mas também alegoria do abismo do tempo -, tentando pôr à vista a estrutura essencial da sua obra (obra que, em si mesma, quer deixar ver esse esqueleto, surgindo destinado ao olhar alegórico), tornou-se um dos principais objetivos de Benjamin, que pretendia também promover a revalorização desse procedimento estético.

Ainda no percurso do contexto da fundamentação de sua crítica ou teoria do conhecimento, Walter Benjamin alarga suas considerações na textura escritural presente no livro das Passagens e enfaticamente ressaltadas no caderno $N$ - Teoria do conhecimento, Teoria do progresso. Envoltos numa disposição metacrítica acerca da possibilidade do conhecimento, ali também estão acentuados tanto a planta teórica da

\footnotetext{
${ }^{22}$ Ibidem, pp.196-197.

${ }^{23}$ Ibidem, p. 200.
} 
obra que ainda está por vir, quanto o cerne, o núcleo epistemológico do pensamento benjaminiano. Montando uma colagem material através da idealização do projeto em torno das passagens parisienses (que tem no centro a figura do flaneur), Benjamin ocupa-se de uma crítica às teorias ditas míticas da história, atacando fundamentalmente, o mito do automático "progresso" histórico e, por conseguinte, teleológico, que fora cristalizado, propagado e acentuado pelo historicismo durante a ascensão das correntes historiográficas européias no século XIX.

Poderíamos afirmar que o fascínio apresentado por Benjamin pelo barroco, nasce da tentativa de compreender lançar apontamentos sobre a lei oculta de um determinado procedimento estético que teve aqui, nesta época, o seu clímax e que foi, com efeito, o procedimento alegórico. É deste esforço, que procurou levar a cabo, que nasceu a sua obra. Tal como uma obra "refletindo" (no pensamento) a estrutura arquitetônica da cidade de Paris e das galerias francesas do século XIX, ela é construída a partir de um método, tão caro ao presente trabalho, o qual Benjamin chama de método da montagem..$^{24}$

Para Benjamin, a cidade de Paris cristaliza um cenário cultural altamente esclarecedor do movimento da arte enquanto mercadoria, uma vez que a cidade materializa e irradia o sonho da modernidade, a ilusão da novidade na circulação das mercadorias e da moda. Diante disso, é revelador o esforço de Benjamin com relação ao trato do problema histórico que deveria tomar configuração a partir da envergadura metodológica de seu projeto. Consciente de que tal questão não seria alcançada simplesmente por meio de um dito "materialismo histórico vulgar", Benjamin procurou desvincular-se da ortodoxia marxista referente à relação causal entre aspectos da gênese econômica e superestrutura.

Um problema central do materialismo histórico a ser considerado: será que a compreensão marxista da história tem que ser necessariamente adquirida ao preço da visibilidade [Anschaulichkeit] da história? Ou: de que maneira seria possível conciliar o incremento da visibilidade com a realização do método marxista? A primeira etapa desse caminho será aplicar à história o princípio da montagem. Isto é: erguer as grandes construções a partir de elementos minúsculos, recortados com clareza e precisão. E, mesmo, descobrir na análise do

\footnotetext{
${ }^{24} \mathrm{O}$ método da montagem, na perspectiva benjaminiana, possibilita a formação de uma imagem do todo a partir da reunião dos "cacos da história". Os "fragmentos" justapostos apontam para uma representação do todo.
} 
pequeno momento individual o cristal do acontecimento total. Portanto, romper com o naturalismo histórico vulgar. Apreender a construção da história como tal. ${ }^{25}$

O foco de análise do autor fecha-se, então, num complexo artefato urbano, avaliando, em suas dimensões materiais e simbólicas, não apenas a cidade de Paris, mas também a espacialização do capitalismo e da arte moderna. É, pois, no alargamento deste horizonte, acerca da espacialização do capitalismo e da arte moderna, onde se dimensiona a problematização histórica do projeto das Passagens. A análise benjaminiana coloca o século XIX em relação com século XX. Por fim, podemos afirmar que o gesto alegórico enquanto forma de representação, segundo Benjamin, é nossa única saída, o caminho pelo qual podemos expressar a multiplicidade em que a cultura se apresenta.

\section{Referências}

ASSOUN, Paul-Laurent. A escola de Frankfurt. São Paulo: Ed. Ática, 1991.

BENJAMIN, Andrew; OSBORNE, Peter. A filosofia de Walter Benjamin: Destruição e experiência. Rio de Janeiro: Jorge Zahar Editora, 1997.

BENJAMIN, Walter. Origem do drama barroco alemão. Trad. br. de Sérgio Paulo Rouanet. São Paulo: Brasiliense, 1984.

Obras escolhidas I: magia e técnica, arte e política. Trad. br. de Sérgio Paulo Rouanet. São Paulo: Brasiliense, 1994.

Obras escolhidas III: Charles Baudelaire, um lírico no auge do capitalismo. Trad. br. de Carlos Barbosa e Hemerson Baptista. São Paulo: Brasiliense, 1994.

Passagens. Trad. br. de Irene Aron. Belo Horizonte: Editora da UFMG, 2007.

BOLLE, Willi. Fisiognomia da metrópole moderna: representação da história em Walter Benjamin. São Paulo: EDUSP, 2000.

CALLADO, Tereza de Castro. Walter Benjamin e a Experiência da Origem. Fortaleza: Ed. UECE, 2006.

O comportamento ex-officio do estadista na teoria da soberania em Origem do Drama Barroco Alemão. in Ética e Metafísica. Fortaleza: Ed. UECE, 2007.

\footnotetext{
${ }^{25}$ BENJAMIN, Walter. Passagens, p.503, [N 2,6].
} 
. O drama da alegoria no século XVII Barroco. In Kalagatos - Revista de Filosofia / Universidade Estadual do Ceará. Mestrado Acadêmico em Filosofia. - v.1, n.1, Fortaleza: Ed. UECE, 2004.

GAGNEBIN, Jeanne Marie. História e narração em Walter Benjamin. São Paulo: Perspectiva, 2007.

HEIDEGGER, Martin. "A essência da linguagem", in: A caminho da linguagem. Petrópoles: Vozes, 2003.

KONDER Leandro. O marxismo da melancolia. Rio de Janeiro: Campus, 1989.

LEIBNIZ, G. W. Novos ensaios sobre o entendimento humano. Trad. Luis João Baraúna. Col. Os Pensadores, São Paulo: Nova Cultural, 1999.

LEIBINZ, G. W. Novos ensaios sobre o entendimento humano. Trad. Luis João Baraúna. Col. Os Pensadores, São Paulo: Nova Cultural, 1999.

LÖWY, Michael. Walter Benjamin: aviso de incêndio. São Paulo: Boitempo, 2005.

MARRAMAO, Giacomo. Poder e secularização: As categorias do tempo. São Paulo: Editora da Universidade Estadual Paulista (UNESP), 1995.

ROUANET, S. P. Teoria crítica e psicanálise. Rio de Janeiro: Tempo Brasileiro, 1989. Édipo e o Anjo: Itinerários freudianos em Walter Benjamin. Rio de Janeiro: Edições Tempo Brasileiro Ltda, 2008. 
